\section{KONSEP RUMAH MENGGUNAKAN ENERGI SURYA}

\author{
Rusdi HA
}

Rusdi HA adalah Guru Besar Teknik Sipil di Universitas Lambung Mangkurat. Dia lulus S1 Teknik Sipil tahun 1974 di ITB. S2 Manajemen konstruksi tahun 1994 dan S3 Teknik Sipil tahun 1997 lulus dari Strathclyde University, Glasgow, UK Sebelum menjadi staf pengajar, Rusd telah bekerja dibeberapa perusahan kontraktor dan konsultan. Menjadi staf pengajar pada tahun 1981, dan menjadi Guru Besar sejak 2005 rusdiha@yahoo.co.uk
Konsumsi energi nasional pada tahun 2013 adalah 1,243 juta setara barel minyak (SBM), 94,6\%nya adalah energi fosil. Energi baru dan terbarukan (EBT) hanya 5,4\%. Konsumsi energi rumah tangga masih menempati proporsi terbesar, hampir di setiap daerah. Dari hal tersebut sangat beralasan bila pengalihan energi fosil ke EBT perlu difokuskan pada rumah tangga. Tujuan penelitian adalah membuat konsep sistem rumah yang memakai energi suya secara maksimal. Penelitian ini dibatasi sampai dengan membuat usulan konsep untuk rumah tipe 36 , terbatas hanya pada ide constructibiliy pemakaian energi surya. Didapat kebutuhan panel surya adalah 800 watt dan battery penyimpanan yang diperlukan berkapasitas 5,346 KWh. Total biaya investasi (conceptual budgetting) adalah sekitar Rp 23 juta, untuk daya maksimum 800 watt. Biaya ini setara dengan biaya perbulan Rp. 91.058,-. Dilihat dari biaya dalam tahap konsep ini, pembuatan rumah dengan konsep tenaga surya cukup layak untuk diimplementasikan.

Kata kunci: Energi baru terbarukan (EBT), Panel surya

www.buletinppi.ulm.ac.id

Tetapi pemanfaatan EBT di Indonesia menghadapi beberapa kendala, antara lain:

- Harga jual energi fosil masih terlalu rendah, dibandingkan dengan negara lain, sehingga kecenderungan memakai energi fosil masih sangat kuat.

- Komponen utama teknologi pembuatan EBT masih harus mengimpor dari luar negeri.

- Biaya investasi pembangunan instalasi EBT tinggi, jadi memerlukan modal awal yang besar.

- Data potensi sumberdaya belum tersedia dengan lengkap.

- Harga belum bisa bersaing dengan energi fosil.

- Teknologi dalam menghadapi fluktuasi sumber energi belum matang.

Konsumsi energi rumah tangga masih menempati proporsi terbesar, hampir di setiap daerah. Dari hal tersebut sangat beralasan bila pengalihan energi fosil ke EBT perlu difokuskan pada rumah tangga.

Implementasi energi surya sudah bisa diterapkan di Indonesia dengan melihat beberapa faktor. Yang pertama adalah teknologi untuk energi surya sudah tersedia di Indonesia baik teknologi panel surya maupun teknologi penyimpan energi (battery). Yang kedua yang paling utama adalah energi matahari tersedia berlimpah karena posisi Indonesia secara geografis terletak di katulistiwa. Kemudian, negara lain yang potensi geografisnya berada lebih rendah dari Indonesia, seperti Swedia, Australia, dll., telah mengimplementasikan EBT secara intensif termasuk energi surya.

- harga bahan bakar tidak mempengaruhi. 
Tujuan penelitian adalah membuat konsep sistem rumah yang memakai energi suya secara maksimal.

Penelitian ini dibatasi sampai dengan membuat usulan konsep untuk rumah tipe 36 , berdasarkan sumber daya teknologi energi surya yang tersedia. Penelitian ini juga terbatas hanya pada ide constructibiliy pemakaian energi surya, bukan electrical generation technology.

Energi matahari merupakan energi yang utama bagi kehidupan di bumi ini. Berbagai jenis energi, baik yang terbarukan maupun tak-terbarukan merupakan bentuk turunan dari energi ini baik secara langsung maupun tidak langsung. Indonesia memiliki sekitar $4.8 \mathrm{KWh} / \mathrm{m} 2 /$ hari (Alamendah, 2011).

Berikut ini adalah beberapa bentuk energi yang merupakan turunan dari energi matahari misalnya:

- Energi angin yang timbul akibat adanya perbedan suhu dan tekanan satu tempat dengan tempat lain sebagai efek energi panas matahari.

- Energi air karena adanya siklus hidrologi akibat dari energi panas matahari yang mengenai bumi.

- Energi biomassa karena adanya fotosintesis dari tumbuhan yang notabene menggunakan energi matahari.

- Energi gelombang laut yang muncul akibat energi angin.

- Energi fosil yang merupakan bentuk lain dari energi biomassa yang telah mengalami proses selama berjuta-juta tahun.

Selain itu energi panas matahari juga berperan penting dalam menjaga kehidupan di bumi ini. Tanpa adanya energi panas dari matahari maka seluruh kehidupan di muka bumi ini pasti akan musnah karena permukaan bumi akan sangat dingin dan tidak ada makluk yang sanggup hidup di bumi.

Energi surya adalah energi yang berupa panas dan cahaya yang dipancarkan matahari. Energi surya (matahari) merupakan salah satu sumber energi terbarukan yang paling penting. Indonesia mempunyai potensi energi surya yang melimpah. Namun melimpahnya sumber energi surya di Indonesia belum dimanfaatkan secara optimal.

Matahari adalah sumber energi yang memancarkan energi sangat besarnya ke permukaan bumi. Permeter persegi permukaan bumi menerima hingga 1000 watt energi matahari. Sekitar $30 \%$ energi tersebut dipantulkan kembali luar angkasa, dan sisanya diserap oleh awan, lautan, dan daratan. Jumlah energi yang diserap oleh atmosfer, lautan, dan daratan bumi sekitar 3.850.000 eksajoule (EJ $=1018$ joule) per tahun. Untuk melukiskan besarnya potensi energi surya, energi surya yang diterima bumi dalam waktu satu jam saja setara dengan jumlah energi yang digunakan dunia selama satu tahun lebih.

Beberapa Pembangkit Listrik Tenaga Surya (PLTS) di Indonesia antara lain (Alamendah, 2011):

- Pembangkit Listrik Tenaga Surya (PLTS) di Kabupaten Karangasem dan Bangli, Bali dengan kapasitas masing-masing $1 \mathrm{MW}$

- PLTS di pulau-pulau Nusa Tenggara Barat yang meliputi Pulau Gili Trawangan berkapasitas $600 \mathrm{kWp}$, Pulau Gili Air (160 kWp), serta Pulau Gili Meno (60 kWp), dan di Pulau Medang, Sekotok, Moyo, Bajo Pulo, Maringkik, dan Lantung dengan total kapasitas $900 \mathrm{kWp}$.

- PLTS di Nusa Tenggara Timur yang meliputi PLTS Raijua (Kabupaten Sabu Raijua) berkapasitas 150 kilo kWp, PLTS Nule (Kab. Alor) berkapasitas $250 \mathrm{kWp}$, PLTS Pura (Kab. Alor) berkapasitas $175 \mathrm{kWp}$, dan PLTS Solor Barat (Kab. Flores Timur) berkapasitas 275 kWp.

\section{Tipikal Konsumsi Energi Rumah Tangga}

Dalam perancangan sistem energi di dalam rumah, perlu perkiraan konsumsi untuk sebuah rumah. Sebuah rumah dapat dibagi menjadi beberapa ruang, dimana setiap ruang mempunyai kebutuhan energi yang spesifik. Menurut PT Energy Management Indonesia (2016) ada 4 macam ruang yang perlu dihitung konsumsi energinya masing-masing, yaitu: ruang keluarga/kamar, dapur, dan kamar mandi

Ruang Keluarga/Kamar

Pada ruang keluarga, peralatan yang mungkin adalah TV set, audio/stereo set, AC split $1 / 2 \mathrm{PK}$, komputer, lampu hemat listrik dan kipas angin. Tabel 1 dan Tabel 2 dibawah ini adalah tipikal konsumsi listrik dan lama pemakaian per hari.

Tabel 1 Peralatan Listrik di Ruang keluarga

\begin{tabular}{|l|l|l|l|}
\hline No. & Alat & Watt & $\begin{array}{l}\text { Durasi } \\
\text { (jam) }\end{array}$ \\
\hline 1 & TV Set & 150 & 8 \\
\hline 2 & Audio/stereo set & 50 & 2 \\
\hline 3 & AC Split $1 / 2$ PK & 430 & 8 \\
\hline 4 & Komputer & 140 & 5 \\
\hline 5 & $\begin{array}{l}\text { Lampu hemat } \\
\text { listrik }\end{array}$ & 12 & 8 \\
\hline 6 & Kipas angin & 103 & 8 \\
\hline
\end{tabular}

Tabel 2 Peralatan Listrik di Dapur

\begin{tabular}{|l|l|l|l|}
\hline No & Alat & Watt & $\begin{array}{l}\text { Durasi } \\
\text { (jam) }\end{array}$ \\
\hline 1 & Microwave & 1270 & 0,5 \\
\hline 2 & Blender & 130 & 0,5 \\
\hline 3 & Kompor listrik & 380 & 4 \\
\hline 4 & Magic jar & 465 & 1 \\
\hline 5 & $\begin{array}{l}\text { Kulkas on } \\
\text { standby }\end{array}$ & 50 & 12 \\
\cline { 2 - 4 } & 12 & 12 \\
\hline 6 & Setrika & 300 & 1 \\
\hline
\end{tabular}




\begin{tabular}{|c|c|c|c|}
\hline \multirow[b]{2}{*}{7} & \multirow{2}{*}{$\begin{array}{l}\text { Dispenser } \\
\text { on } \\
\text { standby }\end{array}$} & 250 & 2 \\
\hline & & 6 & 22 \\
\hline 8 & $\begin{array}{l}\text { Pemanggang } \\
\text { roti }\end{array}$ & 380 & 0,5 \\
\hline
\end{tabular}

\section{Metode}

\section{Pengumpulan Data Energi Radiasi Matahari}

Energi radiasi matahari yang bisa diambil perlu diketahui. Besarnya radiasi tipikal untuk daerah di Indonesia dapat dihitung dari data yang tersedia dari literatur. Jam efektif per hari serta hari efektif per tahun lamanya matahari bersinar dapat dipakai untuk memperhitungkan energi yang dapat dipanen.

\section{Pengumpulan Data Jenis Panel Surya dan Alat Penyimpan}

Ada beberapa jenis panel surya tersedia di Indonesia. Harga relatif masih tinggi, tetapi ada trend penurunan harga pada akhir-akhir ini.

\section{Perhitungan Kebutuhan Energi Rumah Sederhana}

Dari tipikal kebutuhan peralatan setiap jenis ruang, dapat dihitung keperluan energi setiap ruang. Bila diketahui jumlah ruangan setiap rumah, maka kebutuhan total energi dapat dihitung.

\section{Pembuatan Konsep RES}

Konsep RES yang akan dibuat dibuat 2 macam. Konsep yang pertama adalah RES yang sepenuhnya memakai energi surya. Sedangkan konsep yang kedua adalah RES yang memakai energi surya sebagai komplemen.

\section{Hasil Analisa}

Konsep RES yang telah dibuat, diimplementasikan pada rancangan sederhana yang nyata. Pada rancangan ini kemudian dilakukan perhitungan kelayakan teknis dan ekonomi.

\section{Data Energi Radiasi Matahari}

Terkait dengan energi surya, sebagai negara tropis, Indonesia mempunyai potensi energi surya yang cukup besar. Berdasarkan data penyinaran matahari yang dihimpun dari 18 lokasi di Indonesia, radiasi surya di Indonesia dapat diklasifikasikan berturut-turut sebagai berikut: untuk kawasan barat dan timur Indonesia dengan distribusi penyinaran di Kawasan Barat Indonesia (KBI) sekitar 4,5 $\mathrm{kWh} / \mathrm{m}^{2} /$ hari dengan variasi bulanan sekitar $10 \%$; dan di Kawasan Timur Indonesia (KTI) sekitar 5,1 $\mathrm{kWh} / \mathrm{m}^{2} /$ hari dengan variasi bulanan sekitar $9 \%$. Dengan demikian, potensi energi surya rata-rata Indonesia sekitar $4,8 \mathrm{kWh} / \mathrm{m}^{2} /$ hari dengan variasi bulanan

sekitar

$9 \%$.

(Kementrian Energi Sumber Daya Mineral, 2016)

\section{Kebutuhan Energi pada Rumah Sederhana}

Rumah sederhana diasumsikan dihuni oleh rumah tangga sederhana. Dengan demikian kebutuhan energi yang utama adalah lampu penerangan, kulkas kecil, kipas angin, TV set, setrika dan mesin cuci 2 tabung.

Rumah tangga sederhana dianggap terdiri dari 2 kamar tidur, ruang tamu, ruang makan, dapur dan KM/WC. Peralatan listrik yang diperlukan adalah sbb.: 6 buah lampu, kulkas, rice cooker, kipas angin, TV set dan setrika.

Perhitungan energi yang dipakai setiap hari adalah seperti pada Tabel 3 di bawah ini.

Tabel 3. Kebutuhan Daya Rumah Tangga
\begin{tabular}{|l|l|l|l|l|l|}
\hline No & Jenis Alat & $\begin{array}{l}\text { Daya } \\
\text { (watt) }\end{array}$ & $\begin{array}{l}\text { unit } \\
\text { (buah) }\end{array}$ & $\begin{array}{l}\text { Durasi } \\
\text { (jam) }\end{array}$ & $\begin{array}{l}\text { Jumlah } \\
\text { daya } \\
\text { (KWh) }\end{array}$ \\
\hline 1 & $\begin{array}{l}\text { Lampu } \\
\text { LED5 watt }\end{array}$ & 10 & 5 & 8 & 0,400 \\
\hline 2 & Kipas angin & 100 & 1 & 4 & 0,400 \\
\hline 3 & $\begin{array}{l}\text { TV LED 26 } \\
\text { inch }\end{array}$ & 30 & 1 & 8 & 0,240 \\
\hline 4 & setrika & 300 & 1 & 1 & 0,300 \\
\hline 5 & Rice cooker & 400 & 1 & 1 & 0,400 \\
\hline 6 & $\begin{array}{l}\text { Kulkas on } \\
\text { standby }\end{array}$ & $\begin{array}{l}50 \\
10\end{array}$ & 1 & $\begin{array}{l}12 \\
12\end{array}$ & $\begin{array}{l}0,060 \\
0,012\end{array}$ \\
\hline Jumlah kebutuhan daya/hari (KWH) & 1,812 \\
\hline
\end{tabular}

\section{Kebutuhan Energi Surya dan Penyimpanannya}

Kalau dilihat Tabel 4.1 diatas, maka kebutuhan besarnya watt panel surya adalah 450 watt (rice cooker + kulkas). Sedangkan kalau diperhitungkan kebutuhan daya per hari adalah $1,812 \mathrm{KWH}$, maka dengan durasi radiasi matahari efektif 5 jam per hari diperlukan panel surya $1,812 \mathrm{KWh} / 5 \mathrm{~h}=0,363 \mathrm{KW}=$ 363 watt. Dari kedua nilai watt tersebut maka minimum panel surya 450 watt.

Bila diasumsikan bahwa setiap bulan ada hari hujan (tak bermatahari) selama 3 hari berturutturut, maka selama 3 hari tersebut memakai saving dari 27 hari bermatahari. Kebutuhan 3 hari adalah 3 $x$ 1,812 KWh $=5,346 \mathrm{KWh}$. Kebutuhan ini adalah simpanan energi selama 27 hari. Jadi energi surya harus surplus setiap harinya 5,346 KWh/27h $=0,198$ KW $=198$ watt.

Jadi kebutuhan panel surya untuk harian ditambah untuk penyimpanan adalah $554+198=$ 752 watt. Sehingga kebutuhan panel surya adalah 800 watt. Sedangkan energi yang harus dapat disimpan adalah 5,346 KWh. Berarti battery penyimpan harus mempunyai kapasitas penyimpan sebesar minimum 5, $346 \mathrm{KWh}$. 


\section{Implementasi Konsep Rumah Berenergi Surya Konsep Rumah}

Rancangan rumah adalah berupa rumah tipe 36 dengan 2 kamar tidur. Tata ruang agar dibuat sesederhana mungkin agar mudah penempatan peralatan. Ruang-ruang yang lainnya adalah ruang tamu, ruang makan/dapur dan ruang WC/kamar mandi. Ruang yang juga perlu adalah ruang penempatan battery yang letaknya sedemikian rupa agar mudah diakses dari luar rumah.

Orientasi rumah sedapat mungkin menghadap ke selatan dan mempunyai bentuk atap pelana yang miring kedepan/kebelakang. Dengan bentuk atap yang demikian, pada atap sebelah belakang dapat diletakkan panel surya. Posisi ini sangat baik karena dengan letak geografis diselatan khatulistiwa, maka atap sebelah belakang menghadap ke utara, sehingga menerima radiasi matahari yang maksimal (Gambar 1)

\section{Panel Surya}

Dari kebutuhan energi yang telah dihitung diatas yaitu 800 watt, maka ada beberapa pilihan teknologi yang tersedia di pasar. Panel surya 900 - 1500 watt dengan bobot $40 \mathrm{~kg}$, seharga Rp. 15.188.000,- dapat dipilih untuk diimplementasikan (Lihat Lampiran Brosur 1). Harga ini sudah termasuk kabel penghubung dan inverter.

\section{Battery Penyimpanan}

Battery yang akan digunakan harus mempunyai kapasitas 5,346 KWh. Bila digunakan battery basah 70 Ah, 12 volt, berarti kapasitas battery tersebut 12 $x 70=840 \mathrm{Wh}$. Untuk kapasitas 5,346 berarti diperlukan 5,346/0,84 buah battery $=6,3 \sim 7$ buah battery. Pilihan yang ada di pasaran adalah battery merk GS tipe: N70kapasitas $70 \mathrm{Ah}$, tegangan kerja 12 Volt, harga adalah $\mathrm{Rp} \quad 1.016 .000$ (lihat Lampiran Brosur 2). Total harga battery berarti adalah Rp. 7.122.000,

\section{Perhitungan Biaya}

Dari harga panel surya dan battery penyimpanan (Lampiran 1dan Lampiran 2), maka diperlukan biaya sebesar Rp 22.300.000,- Bila umur rencana 25 tahun, maka perkiraan biaya pertahun ( $i=9 \%$ flat) adalah sebagai berikut:

Biaya total per tahun Rp. 1.092.700,- berarti biaya per bulan adalah sebesar Rp. 91,058,-

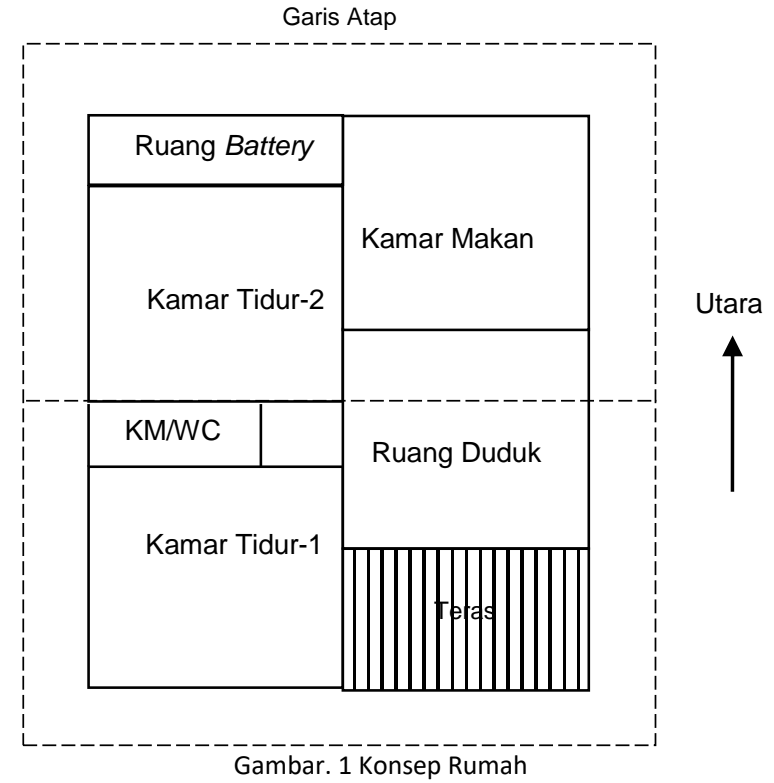

Peralatan Rp.22.300.000,-/25=Rp. 892,000,Bunga Rp. 22.300 .000 x 9\% =Rp. 200,700,Jumlah biaya Rp.1.092.700,-

\section{Kesimpulan}

Pembuatan konsep rumah energi surya dapat direalisasikan. Total harga (conceptual budgetting) adalah sekitar Rp 23 juta, untuk daya maksimum 800 watt. Biaya perbulan adalah sekitar Rp. 91.058,-. Dilihat dari biaya dalam tahap konsep ini, pembuatan rumah dengan konsep tenaga surya cukup layak untuk diimplementasikan.

\section{Saran}

Kontinuitas sistem perumahan sangat tergantung dengan sumber daya peralatan. Ketersediaan peralatan masih belum merata di seluruh daerah. Dengan demikian, vendor yang menyediakan peralatan adalah hal yang penting dalam hal kesinambungan sistem perumahan ini. Tetapi dengan meningkatnya demand akan sumber daya peralatan, diharapkan akan meningkatkan pula ketersediaannya. Yang selanjutnya akan meningkatkan competitiveness pada penyediaan peralatan ini. Selain itu regulasi pada implementasi energi surya perlu dipelajari dan diterapkan. Hal ini berguna untuk langkah-langkah dalam produksi masal sistem perumahan ini.

Penelitian selanjutnya adalah melakukan implementasi fisik. Implementasi ini berupa membuat rumah tipe 36 . Kemudian dilakukan peng-instalasi-an peralatan energi surya, peralatan penyimpan dan peralatan lainnya. Selanjutnya, sistem perumahan ini dioperasikan selama jangka waktu tertentu, untuk melihat reabilitasnya.

\section{Ucapan Terimakasih}

Penulis mengucapkan terimakasih kepada Program Magister Teknik Sipil Universitas Lambung Mangkurat atas bantuan pembiayaan dalam penelitian ini. 


\section{Referensi}

1. Abdullah, N. 2016. Kebutuhan Energi: Indonesia Tertinggi di Asean.

http://industri.bisnis.com/read/20160218/44/52027

5/kebutuhan-energi-indonesia-tertinggi-di-asean. Diakses 14 Juni 2016.

2. Jarass. 1980. Strom aus Wind - Integration einer regenerativen EnergieQuelle, Springer-Verlag, Berlin. Pinske, J.D., 1993, Elektrische Energieerzeugung, 2.vollst. ueberarb. Aufl., BG.Teubner, Stuttgart

3. Sudirham, S. 2010. Distribusi Energi Listrik. \https://eecafedotnet.files. wordpress.com/2011/08/beban-di-jaringandistribusi1.pdf. Akses tgl 16 Juni 2016

4. Direktorat Jenderal Ketenagalistrikan. 2015. Statistik Ketenagaan 2014.

5. PT Energy Management Indonesia. 2016. Menghitung Listrik. http://nasional.kompas.com/read/2008/07/17/1127 5859/yuk.menghitung.pemakaian.listrik.di.rumah

6. Arismunandar, W. 1995. Teknologi Rekayasa Surya. Bandung. Pradnya Paramita.

7. Boyle, G. 1996. Renewable Energy. Milton Keynes. The Open University.

8. Gordon Feller. India Building Large-Scale Solar Thermal Capacity. Available from http://www.ecoworld.org/Home/Articles2.cfm?TID= 325

9. Alamendah. 2014. Energi Surya (Matahari) di Indonesia.https://alamendah.org/2014/11/15/ energi-surya-matahari-di-indonesia/, akses 14 Juni 2016

10. Kementrian Energi Sumber Daya Mineral. 2016. http://www.esdm.go.id/berita/56-artikel/3347pemanfaatan-energi-suryadiindonesia.html?tmpl=component\&print=1\&page 